\title{
ONE-POT SYNTHESIS OF HIGHLY LUMINESCENT CdTe QUANTUM DOTS USING SODIUM TELLURITE AS TELLURIUM SOURCE IN AQUEOUS SOLUTION
}

\author{
YILIN WANG, ${ }^{1 *}$ SHENGYAN LIU \\ College of Chemistry and Chemical Engineering, Guangxi University, Nanning 530004, China
}

(Received: July 19, 2011 - Accepted: February 16, 2012)

\begin{abstract}
A novel technology has been developed for the synthesis of thioglycolic acid (TGA)-capped CdTe quantum dots (QDs) in aqueous medium. The reaction was carried out in air atmosphere with one-pot by using $\mathrm{Na}_{2} \mathrm{TeO}_{3}$ to replace $\mathrm{Te}$ or $\mathrm{Al}_{2} \mathrm{Te}_{3}$. The mechanism for the formation of CdTe QDs is elucidated. The influences of various experimental variables, including refluxing time, $\mathrm{pH}$ value, $\mathrm{Cd} / \mathrm{Te}$ and $\mathrm{Cd} / \mathrm{TGA}$ molar ratios, on the luminescent properties of the obtained CdTe $\mathrm{QDs}$ have been systematically investigated. Furthermore, the obtained QDs were characterized by fourier transform infrared spectra (FTIR), X-ray powder diffraction (XRD) and transmission electron microscopy (TEM), respectively. The results demonstrate that, under the optimized experimental conditions, the obtained CdTe QDs exhibited a narrow photoluminescence band (fwhm33-45 nm) with reproducible room-temperature quantum yields as high as $28 \%$, the emission color is tunable from green to orange with increasing diameter of QDs.
\end{abstract}

Keywords: cadmium tellurium, quantum dots, sodium tellurite, photoluminescence

\section{INTRODUCTION}

Because of their unique optical and electrical properties, CdTe QDs are of great interest in for both fundamental research and technical applications ${ }^{1-4}$. Up to now, many approaches, including organic synthesis ${ }^{5,6}$ and aqueous synthesis ${ }^{7-10}$, have been developed for the preparation of CdTe QDs. Compared with organic synthesis, aqueous synthesis is more reproducible, cheaper, less toxic, and the as-prepared samples are more water-soluble and bio-compatible. Several improvements of the conventional aqueous synthetic method ${ }^{11}$ for thiol-capped CdTe QDs have been reported recently by different groups, including the hydrothermal synthesis ${ }^{12}$, ultrasonic $^{13}$ or microwave ${ }^{14}$ irradiation. However, in most of the aqueous approaches, either Te powder ${ }^{15,16}$ or $\mathrm{Al}_{2} \mathrm{Te}_{3}$ lump ${ }^{17,18}$ is used as tellurium sources. When Te powder is used as a source of tellurium, it must first be reduced by $\mathrm{NaBH}_{4}$ to produce $\mathrm{NaHTe}$ (an unstable compound for its spontaneous oxidation in the presence of oxygen) precursor at lower temperature. Thus, the synthetic procedure involves in two steps, making tellurium precursor (NaHTe), and then synthesizing CdTe QDs. Although $\mathrm{Al}_{2} \mathrm{Te}_{3}$ as an alternative tellurium source can also be used for preparing CdTe QDs, it is moisture-sensitive, and the release of $\mathrm{H}_{2} \mathrm{Te}$ (a highly toxic and flammable gas) is inevitable in the process of preparation. Therefore, it is very necessary to hunt for a stable and less toxic tellurium source for the synthesis of CdTe QDs.

In our previous report ${ }^{19}$, we have provided an alternative approach to prepare TGA-capped CdTe QDs using tellurium dioxide as the Te source. Here we employ sodium tellurite as Te source to prepare TGA-capped CdTe QDs in air atmosphere. The influences of refluxing time, the $\mathrm{pH}$ value of the original solution, the $\mathrm{Cd} / \mathrm{Te}$ molar ratio, and the $\mathrm{Cd} / \mathrm{TGA}$ molar ratio on the luminescence properties of CdTe QDs were investigated systematically. We admit that similar tellurite (potassium tellurite) has been used in CdTe QDs synthesis ${ }^{20}$. However, reducing agent such as $\mathrm{NaBH}_{4}$ was not used in the preparation, and the experimental conditions were not optimized, the luminescence properties of the obtained CdTe QDs were not very good.

\section{EXPERIMENTAL}

\section{Chemicals}

Thioglycolic acid $(90 \%), \mathrm{CdCl}_{2} \cdot 2.5 \mathrm{H}_{2} \mathrm{O}(99 \%), \mathrm{NaBH}_{4}(96 \%)$ and Rhodamine 6G (with a photoluminescence quantum yield of $95 \%$ in anhydrous ethanol) were obtained from Sinopharm Chemical Reagent Co., Ltd (Shanghai, China), $\mathrm{Na}_{2} \mathrm{TeO}_{3}(97 \%$ ) was obtained from Aladdin Chemistry Co., Ltd (Shanghai, China). All chemicals were used as received without further purification. Double deionized water was used throughout the experiment.

\section{Synthesis}

In a typical procedure, $0.4567 \mathrm{~g}(2 \mathrm{mmol}) \mathrm{CdCl}_{2} \cdot 2.5 \mathrm{H}_{2} \mathrm{O}$ was dissolved in $100 \mathrm{ml}$ of deionized water in a 250 -ml three-neck flask, and $0.2 \mathrm{ml}$ thioglycolic acid (TGA) was added while stirring, followed by adjusting the $\mathrm{pH}$ to 11.5 with $1.0 \mathrm{~mol} \cdot \mathrm{L}^{-1} \mathrm{NaOH}$ solution. After several minutes, excess $\mathrm{NaBH}_{4}(0.1 \mathrm{~g})$ and $0.0222 \mathrm{~g}(0.1 \mathrm{mmol}) \mathrm{Na}_{2} \mathrm{TeO}_{3}$ was added successively into the above solution. The mixture was then refluxed at $100^{\circ} \mathrm{C}$ for different time to control the size of the CdTe QDs.

Characterization

The absorption and photoluminescence spectra were measured using a UV-2102 spectrometer and a RF-5301 fluorescence spectrometer, respectively. FTIR spectra were recorded on a Nexus-470 spectrometer. X-ray powder diffraction was taken on a D/MAX 2500V diffractometer equipped with $\mathrm{Cu} \mathrm{K \alpha}$ radiation ( $\lambda=0.15406 \mathrm{~nm}$ ). The morphology measurement was performed using an H-7650 transmission electron microscopy.

\section{Measurement of quantum yields}

The photoluminescence quantum yield( QY) of CdTe QDs was measured according to the method described in ref.21, briefly, rhodamine $6 \mathrm{G}$ was chosen as a reference standard ( $Q Y=95 \%$, in ethanol), the absorbance for the standard and the CdTe QDs samples at the excitation wavelength and the fluorescence spectra of the same solutions were measured, respectively. The expression to calculate quantum yield is provided as following:

$$
Y_{\mathrm{u}}=Y_{\mathrm{s}} \times \frac{F_{\mathrm{u}} \times A_{\mathrm{s}}}{F_{\mathrm{s}} \times A_{\mathrm{u}}}
$$

in Eq.(1), the subscripts $s$ and $u$ denote standard (rhodamine 6G) and test samples, respectively, $Y$ is quantum yield, $F$ is the integrated emission peak area, and $A$ is the absorbance at excitation wavelength.

\section{RESULTS AND DISCUSSION}

\section{Mechanism for the formation of CdTe QDs}

The aqueous synthesis of QDs is often based on the Ostwald ripening phenomenon, and the formation of QDs in solution involves in two stages: nucleation and growth ${ }^{22}$. In this synthesis process, $\mathrm{CdCl}_{2} \cdot 2.5 \mathrm{H}_{2} \mathrm{O}$ and $\mathrm{Na}_{2} \mathrm{TeO}_{3}$ were chosen as precursors, TGA was used as the capping ligand. The following mechanism is proposed to explain the formation of CdTe QDs. Firstly, cadmium thiol complexes were formed in the solution (Eq. (2)), when the $\mathrm{TeO}_{3}{ }^{2-}$ was added to the three-neck flask, it can be reduced by $\mathrm{NaBH}_{4}$ to give $\mathrm{Te}^{2-}$ (Eq. (3)) that reacted with the $\mathrm{Cd}^{2+}$-TGA complexes, resulting in the formation of CdTe nuclear (Eq. (4)). With the CdTe nuclear growing gradually, the CdTe QDs were formed at last (Eq. (5)). In our experiments, we obtained TGA-capped CdTe QDs with tunable size-dependent emission from green to orange (Figure1) by controlling the refluxing time.

$$
\begin{aligned}
& \mathrm{Cd}^{2+}+\mathrm{TGA} \rightarrow \mathrm{Cd}^{2+}-\mathrm{TGA} \\
& 4 \mathrm{TeO}_{3}^{2-}+3 \mathrm{BH}_{4}^{-} \rightarrow 4 \mathrm{Te}^{2-}+3 \mathrm{BO}_{2}^{-}+6 \mathrm{H}_{2} \mathrm{O} \\
& \mathrm{Cd}^{2+}-\mathrm{TGA}+\mathrm{Te}^{2-} \rightarrow \mathrm{CdTe}-\mathrm{TGA} \\
& n \mathrm{CdTe}-\mathrm{TGA} \rightarrow(\mathrm{CdTe}-\mathrm{TGA})_{\mathrm{n}}
\end{aligned}
$$




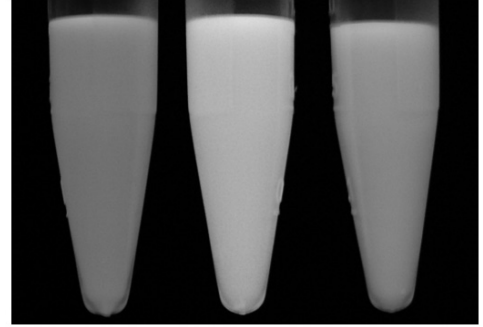

Figure1. Images of the as-prepared CdTe QDs illuminated under an ultraviolet lamp.

\section{Synthetic conditions}

Figure2 shows typical absorption and PL spectra of a size series of CdTe QDs. The spectra were measured on as-prepared CdTe solutions which were taken from the refluxing reaction mixture at different intervals of time and diluted with water. It can be seen, all samples show a well-resolved excitonic absorption peak, indicating the formation of CdTe QDs with narrow size distribution. After $0.5 \mathrm{~h}$ refluxing, an excitonic absorption peak of CdTe QDs appeared at $475 \mathrm{~nm}$, which shifted to longer wavelengths with increasing of reflux time. According to the empirical formula ${ }^{23}$ :

$$
D=\left(9.8127 \times 10^{-7}\right) \lambda^{3}-\left(1.7147 \times 10^{-3}\right) \lambda^{2}+(1.0064) \lambda-194.84
$$

where $\lambda$ is the first absorption maximum. The mean diameter was estimated to $1.5(0.5 \mathrm{~h}), 2.5(1.5 \mathrm{~h}), 3.0(3 \mathrm{~h}), 3.2(5 \mathrm{~h})$ and $3.4 \mathrm{~nm}(9 \mathrm{~h})$, respectively. As described in Figure2, with reflux time increasing from $0.5 \mathrm{~h}$ to $9 \mathrm{~h}$, the PL spectra of CdTe QDs shifts from $509 \mathrm{~nm}$ to $582 \mathrm{~nm}$, the full width at half maximum (FWHM) of the PL spectra is about $33 \mathrm{~nm}\left(\lambda_{\mathrm{em}}=509 \mathrm{~nm}\right)$ and increases up to $45 \mathrm{~nm}(\lambda=582 \mathrm{~nm})$. The PL peaks are located close to the absorption thresholds, which indicate that the photoluminescence of $\mathrm{CdTe}$ QDs is attributed to band-edge or "excitonic" emission. The PLQY of the five samples were calculated to be $7.2 \%, 22.3 \%, 28.1 \%, 28.0 \%$ and $21.0 \%$, respectively. The obtained CdTe QDs exhibited high PLQY of $28 \%$ at the emission wavelength of 553 and $566 \mathrm{~nm}$. Such a QY is higher than that of TGA-capped CdTe QDs synthesized using $\mathrm{Al}_{2} \mathrm{Te}_{3}$ as the tellurium sources (10 $\%)^{11}$, and close to that of synthesized using Te powder as the tellurium sources $(32 \%)^{15}$.

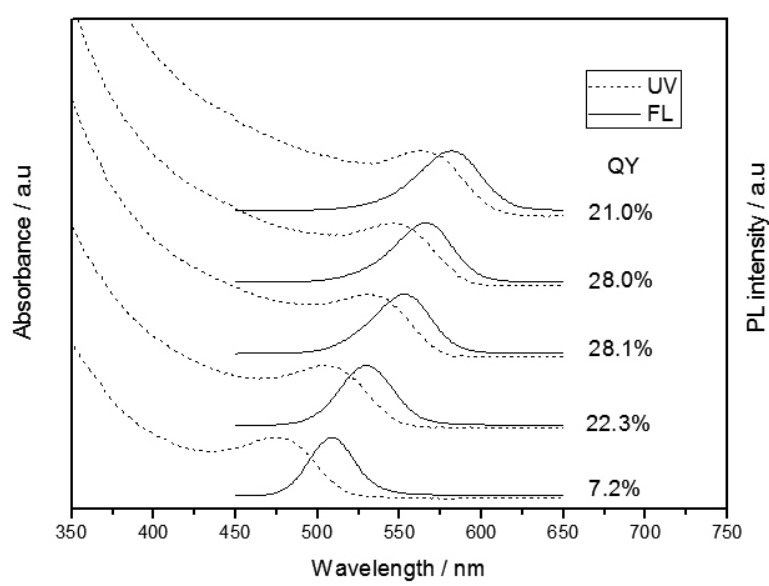

Figure2.Temporal evolution of absorption (dashed line) and PL spectra (solid line) of CdTe QDs

It has been demonstrated that cadmium and thiol can form different polynuclear complexes in water and that the formation of cadmium thiol complexes strongly depends on $\mathrm{pH}$ of the solution ${ }^{24}$. According to ref.11, the recommended $\mathrm{pH}$ value for synthesis of TGA-capped CdTe is 11.2 to 11.8 while the proposed value for the Cd/TGA ratio is 1:2.45. In the present study, the influence of the $\mathrm{pH}$ value of the original solution on the optical properties of CdTe QDs was investigated firstly, and the obtained experimental results are shown in Figure 3. Here, with fixed $\mathrm{Cd} / \mathrm{Te} / \mathrm{TGA}$ (1:0.1:1.9) molar ratio, the solution $\mathrm{pH}$ value was adjusted to $9.5,10.5$, and 11.5 respectively. As can be seen in Figure3, the PL peaks of CdTe shift to longer wavelengths with the increasing of initial $\mathrm{pH}$ value, in comparison with the CdTe QDs obtained at $\mathrm{pH}=9.5$ or 10.5 , the CdTe QDs formed at $\mathrm{pH}=11.5$ have a longer PL peak. The PLQYs of QDs at different initial $\mathrm{pH}$ values all reached a maximum and then declined with the red-shift of PL peak, and initial $\mathrm{pH}$ at 11.5 is in favor of synthesizing CdTe QDs with high PLQY.

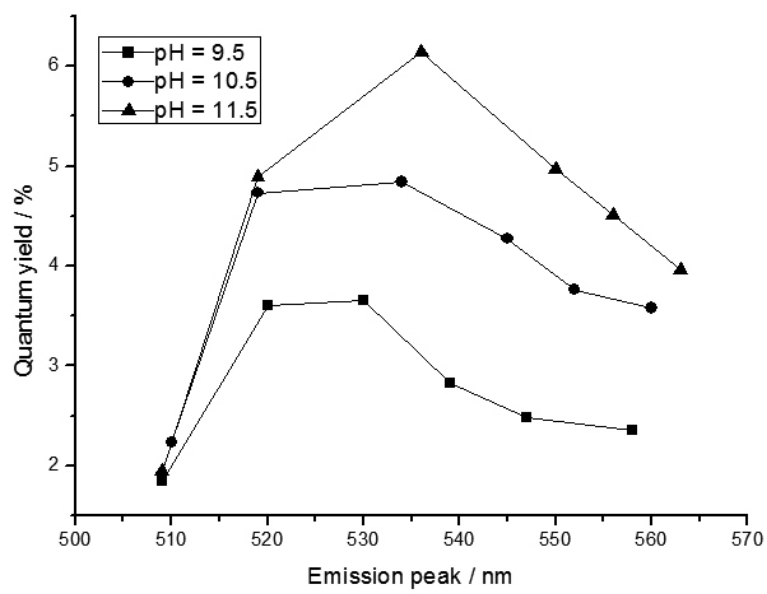

Figure3. PLQYs of CdTe QDs prepared at different initial $\mathrm{pH}$ value.

The $\mathrm{Cd} / \mathrm{Te}$ molar ratio is another important factor that may influence the PLQY of thiol-capped CdTe QDs. In previous reports ${ }^{25-27}$, different $\mathrm{Cd} /$ Te molar ratios (changing from 1:0.2 to 1:0.5) were adopted in the aqueous preparation of CdTe QDs using Te powder or $\mathrm{Al}_{2} \mathrm{Te}_{3}$ lump as tellurium source. In our experiments, the $\mathrm{Cd} / \mathrm{Te}$ molar ratio was varied from 1:0.05 to 1:0.3 with fixed Cd/TGA molar ratio at 1:1.9 and $\mathrm{pH}$ value at 11.5 , we investigated the influence of various $\mathrm{Cd} / \mathrm{Te}$ molar ratios on the PLQY of CdTe QDs, and the obtained experimental results are shown in Figure4A. It can be seen that the QDs show distinguishing PLQY dependent on the stoichiometric ratio of Cd to Te precursors used in the synthesis process. Compared with the CdTe QDs obtained with the other four $\mathrm{Cd} / \mathrm{Te}$ molar ratios, the $\mathrm{CdTe}$ QDs prepared at $\mathrm{Cd} /$ Te molar ratio 1:0.05 possess a high PLQY value. The research ${ }^{28}$ revealed that highly luminescent CdTe QDs possess much fewer Te atoms on the surface than that of CdTe with low luminescence. Here, we suppose that, with fixed the amount of $\mathrm{Cd}$ and TGA, increasing the amount of Te, the relative coverage rate of the particle surface with Te atoms will increase, which results in the low luminescence. So a proper $\mathrm{Cd} / \mathrm{Te}$ molar ratio is important for preparation of high quality CdTe QDs, in our experiment, the optimal ratio is 1:0.05.

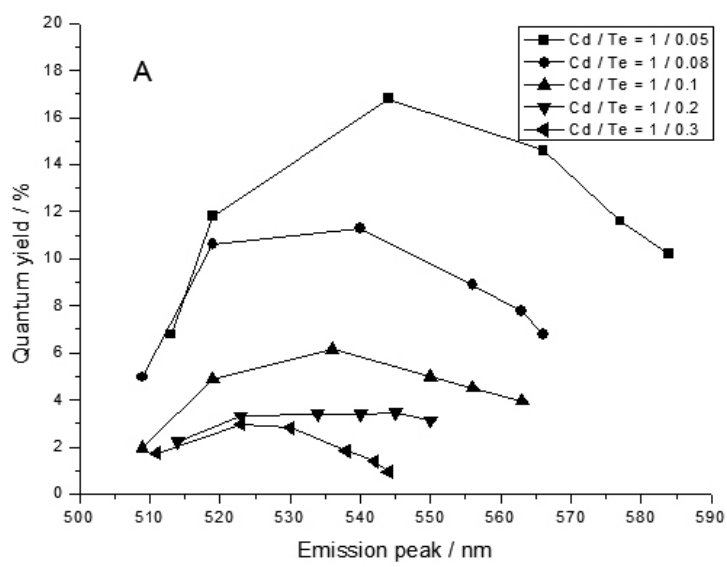




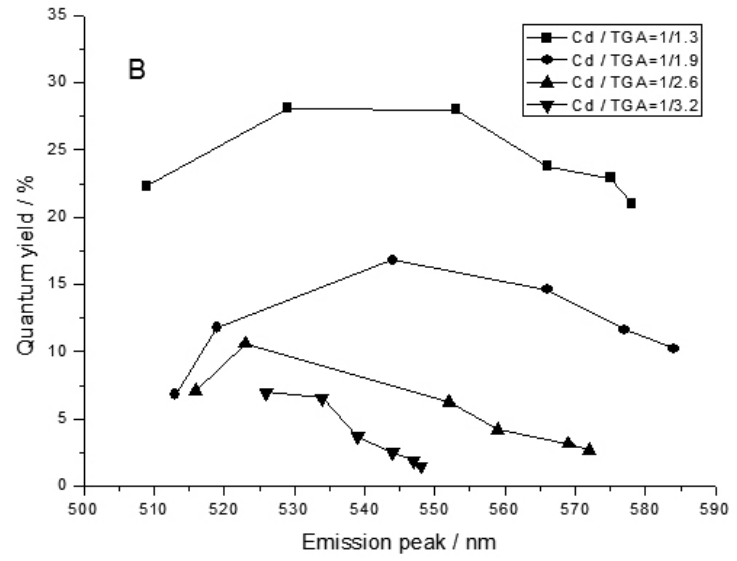

Figure4. PLQYs of CdTe QDs with various molar ratios of $\mathrm{Cd} / \mathrm{Te}(\mathrm{A})$ and Cd/TGA (B).

The passivation of surface sites by ligand stabilizer molecules results in the formation of a favorable structure to remove the dangling bonds from the surface, which can improve the PLQY of QDs. Therefore, the thiol plays an important role in the synthesis of thiol-capped CdTe QDs. However, in most of the "traditional" aqueous approaches ${ }^{11,15}$, the stoichiometric ratio of $\mathrm{Cd}$ to thiol was often set as 1:2.45. In our experiments, the $\mathrm{Cd} / \mathrm{TGA}$ molar ratio was changed from 1:1.3 to $1: 3.2$ with fixed $\mathrm{Cd} / \mathrm{Te}$ molar ratio (1: 0.05$)$ and $\mathrm{pH}$ value (11.5), we investigated the influence of various $\mathrm{Cd} / \mathrm{TGA}$ molar ratios on the PLQY of CdTe QDs. The experimental data in Figure4B show that increasing the Cd/TGA ratio leads to a drastic increase of the PLQY of CdTe QDs, and the maximum PLQYs of CdTe QDs are prepared at Cd/TGA $=1: 1.3$, which was in accord with the research result of ref. 29.

\section{Characterization}

The FTIR spectra of sodium thioglycolate and TGA-capped CdTe QDs are shown in Figure5. Compared to the IR spectra of sodium thioglycolate (solid line), significant changes in the IR spectra of TGA-capped CdTe QDs (dashed line) were observed. First, the stretching vibration of the thiol group $\left(2550 \mathrm{~cm}^{-}\right.$ 1) was absent. Additionally, a significant shift in the asymmetric stretching vibration of the carboxyl group $\left(v_{\text {coo }}=1700 \mathrm{~cm}^{-1}\right.$ to $\left.1585 \mathrm{~cm}^{-1}\right)$ were observed. As reported ${ }^{30}$, due to the formation of covalent bonds between thiols as well as carboxyls and the $\mathrm{Cd}^{2+}$ ions of the surface of QDs, the peaks of - SH and $-\mathrm{COOH}$ groups on the surface of QDs dispersed. It proved that TGA-capped CdTe QDs were formed.

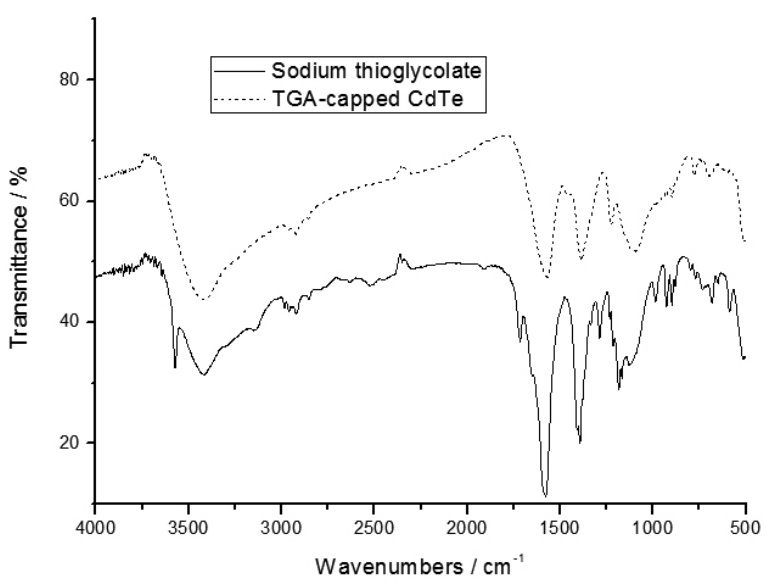

Figure5. FTIR spectra of sodium thioglycolate (solid line) and TGAcapped CdTe QDs (dashed line)

The crystallinity and structure of CdTe QDs were demonstrated by the XRD pattern as revealed in Figure6. XRD pattern of CdTe QDs582 exhibits three peaks that can be assigned to (111), (220), and (311) diffractions corresponding to cubic zinc-blende structure. These peaks are broadened due to finite crystalline size. The particle size can be calculated according to Scherrer's equation ${ }^{31}$ :

$$
L=\frac{0.9 \lambda}{B \cos \theta}
$$

where $L$ is the coherence length, $\lambda$ is the $\mathrm{X}$-ray wavelength $(0.15406 \mathrm{~nm}$ in this study), $B$ is the full width at half maximum of respective diffraction peak, and $\theta$ is the angle of diffraction for (111) plane. In the case of small crystallites, $L=3 / 4 D$, where $D$ is the average diameter of QDs. Based on the reflection peak at $2 \theta$ of 24.5 , an average diameter of QDs582 is calculated as $3.5 \mathrm{~nm}$, which was in accord with the result of the UV-vis absorption peak analysis.

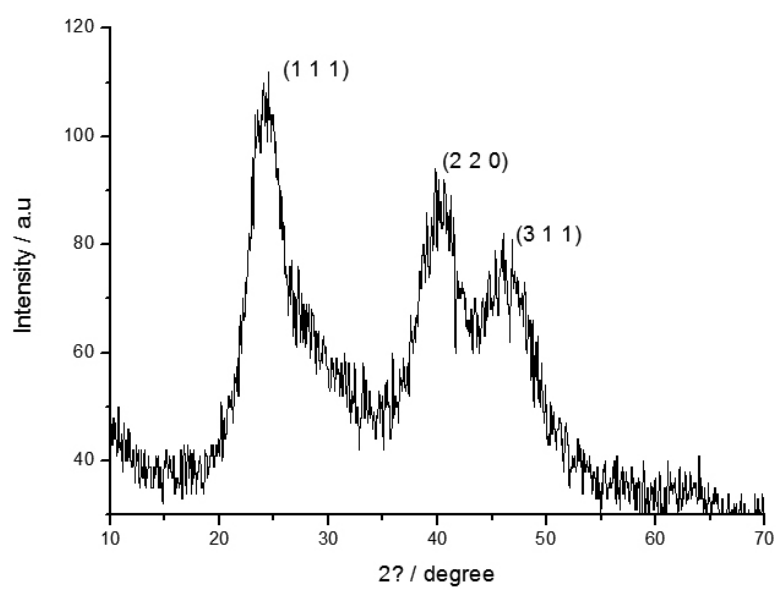

Figure6. XRD pattern of CdTe QDs582

Figure7 shows the TEM and HRTEM images of QDs582. The TEM image confirmed that the size distribution of the as-synthesized CdTe QDs were nearly monodisperse with the average size of about $5.0 \mathrm{~nm}$. The relatively narrow size distribution from the TEM measurements was consistent with the sharp band edge observed in the absorption spectra. The particles were very crystalline with distinct lattice fringes observed in HRTEM, and the lattice spacing of 3.67 A corresponds to the (1 111 ) plane of CdTe.
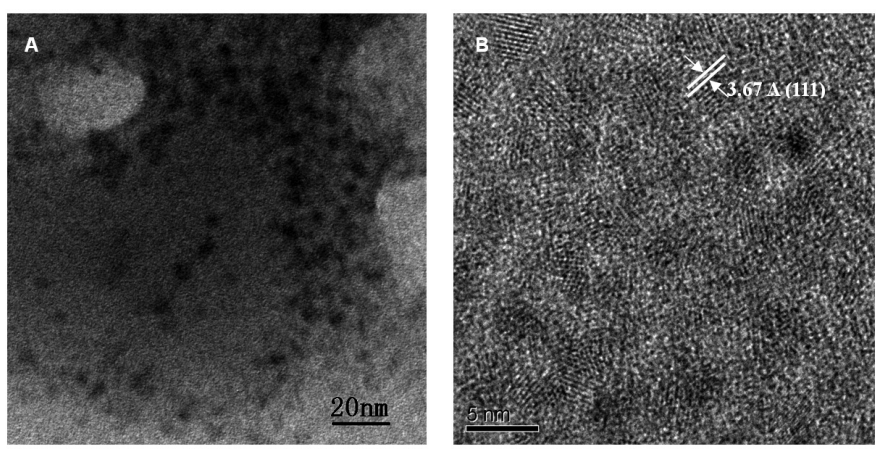

Figure7. TEM (A) and HRTEM (B) image of CdTe QDs582

\section{CONCLUSIONS}

A one-pot method for preparing CdTe QDs using sodium tellurite as tellurium source has been described. The $\mathrm{pH}$ value of the original solution, the $\mathrm{Cd} / \mathrm{Te}$ molar ratio and the Cd/TGA molar ratio play important roles in the synthesis of high quality CdTe QDs. Highly luminescent QDs were prepared at $\mathrm{Cd} / \mathrm{Te} / \mathrm{TGA}=1: 0.05: 1.3$, and $\mathrm{pH}=11.5$. Compared with $\mathrm{Te}$ powder and $\mathrm{Al}_{2} \mathrm{Te}_{3}$ lump route, the new $\mathrm{Na}_{2} \mathrm{TeO}_{3}$ route is an environment-friendly and low-cost synthesis route, which is suited for large-scale synthesis. 


\section{ACKNOWLEDGEMENTS}

Financial support from the National Natural Science Foundation (61066006) and the Scientific Research Foundation of Guangxi University (XBZ110359) are gratefully acknowledged.

\section{REFERENCES}

1. C. Gerhards, C. S. Drost, V. Sgobba, et al. J Phys Chem B, 112, 14482(2008)

2. Y. C. Kobayashi, L. Y. Pan, N. T. Tamai. J Phys Chem C, 113, 11783(2009)

3. B. Y. Han, J. P. Yuan, E. K. Wang. Anal Chem, 81, 5569(2009)

4. X. F. Gao, H. B. Li, W. T. Sun, et al. J Phys Chem C, 113, 7531(2009)

5. C. B. Murray, D. J. Norris, M. G. Bawendi. J Am Chem Soc, 115, 8706(1993)

6. Z. A. Peng, X. G. Peng. J Am Chem Soc, 123, 183 (2001)

7. A. L. Rogach, T. Franzl, T. A. Klar, et al. JPhys Chem C, 111, 14628(2007)

8. H. B. Bao, Y. J. Gong, Z. Li, et al. Chem Mater, 16, 3853(2004)

9. C. L. Wang, H. Zhang, J. H. Zhang, et al. J Phys Chem C, 111, 2465(2007)

10. Y. He, L. M. Sai, H. T. Lu, et al. Chem Mater, 19, 359(2007)

11. N. Gaponik, D. V. Talapin, A. L. Rogach, et al. J Phys Chem B, 106 $7177(2002)$

12. J. Khatei, K. S. R. Koteswara Rao. Mater Chem Phys, 130, 159 (2011)
13. F. D. Menezes, A. Galembeck, S. A. Junior. Ultrason Sonochem, 18, $1008(2011)$

14. Y. He, H. T. Lu,L. M. Sai, et al. J Phys Chem B, 110, 13352(2006)

15. Y. H. Zhang, H. S. Zhang, M. Ma, et al. Appl Surf Sci, 255, 4747(2009)

16. Y. L. Wang, J. P. Lu, Z. F. Tong, et al. J Chil Chem Soc, 54, 274(2009)

17. Y. G. Zheng, S. J. Gao, J. Y. Ying. Adv. Mater. 19, $376(2007)$

18. A. Mandal, N. T. Tamai. J Phys Chem C, 112, 8244 (2008)

19. Y. L. Wang, Z. F. Tong, J. P. Lu, et al. CIESC Journal, 62, 875(2011)

20. M. S. Esadek, J. R. Kumar, S. M. Babu. Curr Appl Phys, 10, 317(2010)

21. J. W. Liu, Y. Zhang, C. W. Ge, et al. Chinese Chem Lett, 20, 977(2009)

22. T. Trindade, P. Brien, N. L. Pickett. Chem Mater, 13, 3843 (2001)

23. W. W. Yu, L. H. Qu, W. Z. Guo, et al. Chem Mater, 15, 2854(2003)

24. V. Swayambunathan, D. Hayes, K. H. Schmidt, et al. J Am Chem Soc, 112, 3831(1990)

25. Y. F. Liu, J. S. Yu. J Colloid Interf Sci, 333, 690(2009)

26. Y. L. Zeng, C. R. Tang, H. W. Wang. Spectrochim Acta A, 70, 966(2008)

27. X. J. Feng, Q. K. Shang, H. J. Liu, et al. J Lumin, 130, 648(2010)

28. H. Borchert, D. V. Talapin, N. Gaponik, et al. J Phys Chem B, 107, 9662(2003)

29. A. Shavel, N. Gaponik, A. Eychmu1ller. JPhys Chem B, 110, 19280(2006)

30. M. Y. Li, H. M. Zhou, H. Y. Zhang, et al. J Lumin, 130, 1935(2010)

31. M. S. A. El-sadek, A. Y. Nooralden, S. M. Babu, et al. Opt Commun, 284, 2900(2011) 